\title{
Wound drains in posterior spinal surgery: a meta-analysis
}

Yancheng $\mathrm{Liu}^{1+}$, Yaomin $\mathrm{Li}^{2+}$ and Jun Miao ${ }^{1 *}$

\begin{abstract}
Background: The use of drains following posterior spinal surgery is controversial. Thus, the aim of this meta-analysis was to review the advantages and adverse effects of closed suction drainage systems in posterior spinal surgery.

Methods: All randomized and non-randomized controlled trials comparing the use of closed suction drainage with no drainage in posterior spinal surgery were sought in PubMed, Medicine, Embase, and other Internet databases. All of the literature was searched and assessed by two independent reviewers, according to the standards of Cochrane systematic reviews. Data on functional and radiological outcomes in the two groups were pooled, which were then analyzed with RevMan software, version 5.2.

Results: Four randomized controlled trials (RCTs) and four non-RCTs met the inclusion criteria. Meta-analysis revealed that no significant differences were found regarding wound infection $(P=0.83)$, hematoma $(P=0.48)$, neurological injury $(P=0.21)$, estimated blood loss $(P=0.59)$, or dry and moderate dressing drainage between the groups. The number of patients with saturated dressings was larger in the no drainage group $(P=0.002)$.

Conclusions: There is no obvious evidence to support the application of closed suction drains for posterior spinal surgery. Because of the limited quality of the evidence currently available, more high-quality RCTs with better experimental designs and larger patient samples should be performed.
\end{abstract}

Keywords: Spine, Posterior, Drain, Meta-analysis

\section{Background}

Level of evidence: III

Closed suction drainage is commonly used in orthopedic surgery. The aim of using closed suction drainage is the prevention of the formation of hematomas [1]. Postoperative hematoma in the operative field can increase tension on incisions, delay wound healing, and lead to wound infection [2]. Moreover, epidural hematoma can lead to spinal cord compression and even paralysis in spinal surgery [3-5]. However, a few studies have demonstrated that closed suction drainage has no benefit in joint arthroplasty and spinal surgery [6, 7]. In contrast, closed suction drainage could cause retrograde infection, increase postoperative blood loss, and the need for transfusion $[8,9]$.

The use of closed suction drainage in posterior spinal surgery remains controversial [10-15]. Therefore, we

\footnotetext{
* Correspondence: tianjinyymiaojun@163.com

${ }^{\dagger}$ Equal contributors

'Department of Spine Surgery, Tianjin Hospital, Tianjin 300211, People's

Republic of China

Full list of author information is available at the end of the article
}

conducted a meta-analysis, pooling the data from randomized controlled trials (RCTs) and non-RCTs to provide an evidence-based judgment regarding the use of closed suction drainage in posterior spinal surgery.

\section{Methods \\ Search strategy}

Electronic databases, including the Cochrane Library, Medline (1966-2015.10), PubMed (1966-2015.10), Embase (1980-2015.10), and ScienceDirect (1985-2015.10), were searched. Gray studies were identified from the references of the included literature. No language restrictions were applied. The search process was conducted as illustrated in Fig. 1. The keywords "Drain OR Drainage", "spine OR spinal," and "posterior" were used in combination with the Boolean operators AND and OR.

\section{Selection criteria}

Studies were considered eligible for inclusion if they met the following criteria: (1) the patients underwent primary 


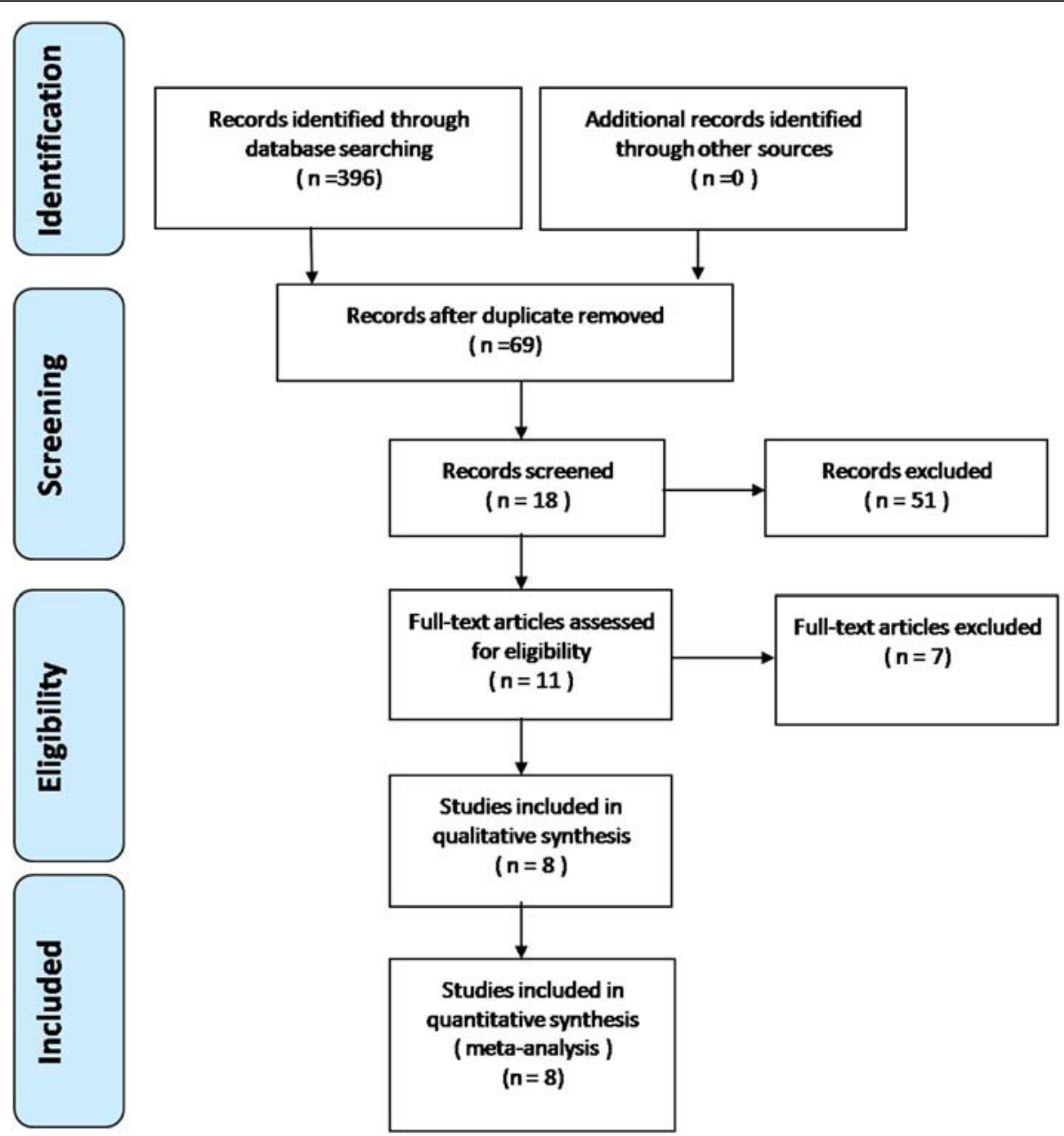

Fig. 1 Flowchart of the study selection process

posterior spinal surgery, (2) the intervention was the use of drainage compared to no drainage, (3) the outcomes included blood loss, transfusion, and complication, and (4) the study was a published or unpublished controlled clinical trial.

Exclusion criteria: Patients were excluded from the metaanalysis if they had a neoplastic etiology (i.e., metastasis or myeloma), infection, traumatic fracture, serious osteoporosis, metal sensitivity, or mental illness.

\section{Quality assessment}

Two reviewers completed the search process independently. Disagreement was resolved by consulting a third

Table 1 Characteristics of included studies

\begin{tabular}{lllllll}
\hline Studies & Design & Cases (D/C) & Mean age (D/C) & Male (D/C) & Surgical procedure/patient population & Follow-up \\
\hline Payne et al. [14] & RCT & $103 / 97$ & NA & NA & Single-level lumbar laminectomy & 2 weeks \\
Blank et al. [10] & RCT & $18 / 12$ & 13.9 & 18 & Posterior spinal fusion and instrumentation & Discharge \\
Brown and Brookfield [1 1] & RCT & $42 / 41$ & $67.4 / 67.4$ & NA & Extensive lumbar spine surgery & Discharge \\
Sen et al. [15] & PCT & $41 / 38$ & 46.4 & 45 & Unilateral, single-level lumbar disc herniation & $6-12$ months \\
Mirzai et al. [18] & RCT & $22 / 28$ & $47 / 47$ & $16 / 17$ & Hemipartial laminectomy and flavectomy $\quad 6$ months \\
Kanayama et al. [13] & CCT & $298 / 262$ & $44 / 48$ & $190 / 168$ & Single-level lumbar decompression surgery $\quad$ Discharge \\
Walid 2011 & CCT & $285 / 117$ & 57.3 & 173 & Posterior lumbar interbody fusion & Discharge \\
Diab et al. [12] & PCT & $324 / 176$ & $15.7 / 15.6$ & $59 / 43$ & Posterior spinal fusion and instrumentation 2 years
\end{tabular}

$D$ drainage, $C$ no drainage, $R C T$ randomized controlled trial, $P C T$ prospective controlled trial, $C C T$ case controlled trial, NA no available 


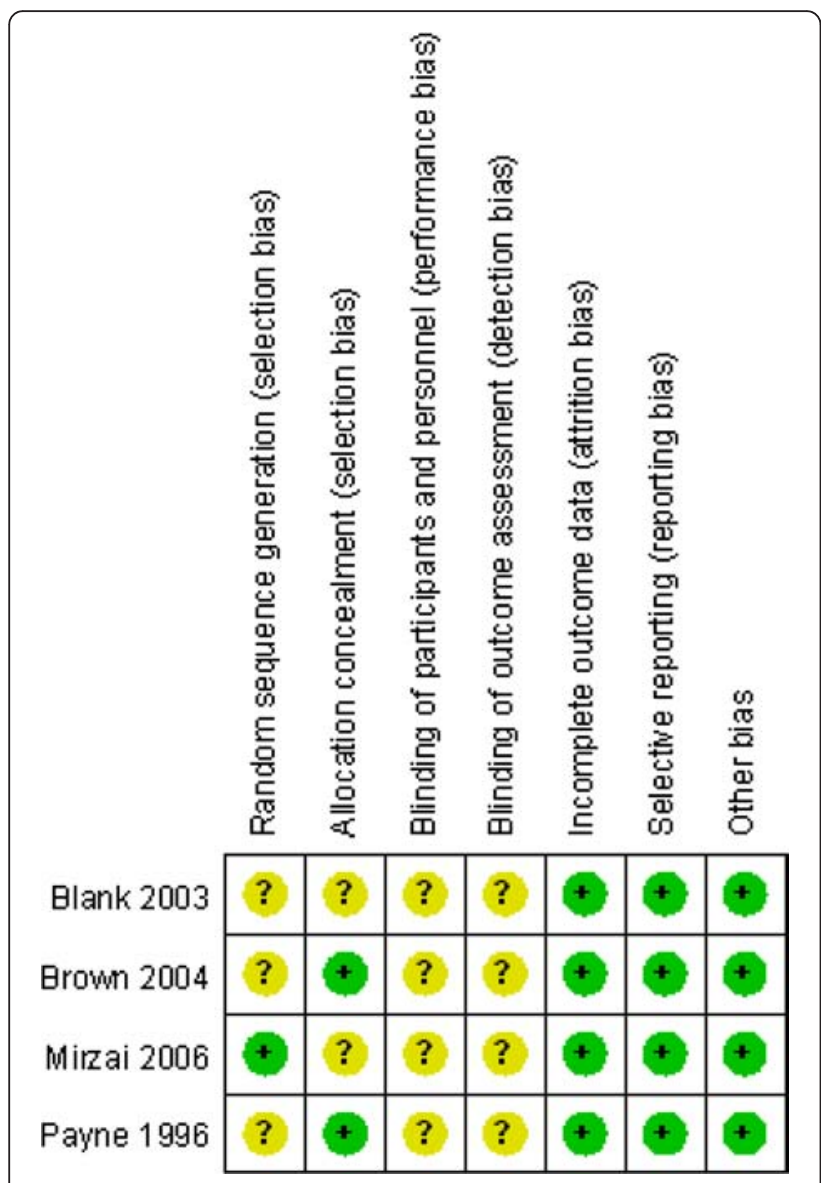

Fig. 2 The summary of bias risk of randomized controlled trials reviewer. Quality assessment for randomized trials was conducted according to a modification of the generic evaluation tool used by the Cochrane Bone, Joint and Muscle Trauma Group [16] and the index for nonrandomized studies (MINORS) form for non-randomized clinical trials [17]. The methodological quality of each trial was scored from 0 to 24 .

\section{Data extraction}

Two researchers independently extracted the data from the included literature. In cases of incomplete data, the study authors were consulted for details. The following data were extracted: first author name, year of publication, intervening measures, comparable baseline data, sample size, and outcome measurements. Other relevant parameters were also extracted from individual studies.

\section{Data analysis and statistical methods}

The pooled data were analyzed using RevMan software, version 5.1 (The Cochrane Collaboration, Oxford, United Kingdom). Heterogeneity was estimated depending on the values of $P$ and $I^{2}$ using the standard chi-square test. When $I^{2}>50 \%, P<0.1$ was considered to indicate significant heterogeneity. Therefore, a random-effects model was applied for data analysis. A fixed-effects model was used when no significant heterogeneity was found. In cases of significant heterogeneity, subgroup analysis was performed to investigate sources. For continuous outcomes, mean differences (MDs) and $95 \%$ confidence intervals (CIs) are presented. Risk difference (RD) and $95 \%$ CIs were calculated for dichotomous data.

Table 2 Quality assessment for non-randomized trials

\begin{tabular}{|c|c|c|c|c|}
\hline Quality assessment for non-randomized trials & Sen et al. [15] & Kanayama et al. [13] & Walid 2011 & Diab et al. [12] \\
\hline A clearly stated aim & 2 & 2 & 2 & 2 \\
\hline Inclusion of consecutive patients & 2 & 1 & 1 & 2 \\
\hline Prospective data collection & 2 & 2 & 2 & 2 \\
\hline Endpoints appropriate to the aim of the study & 1 & 1 & 1 & 1 \\
\hline Unbiased assessment of the study endpoint & 1 & 1 & 1 & 0 \\
\hline A follow-up period appropriate to the aims of study & 2 & 2 & 2 & 2 \\
\hline Less than $5 \%$ loss to follow-up & 2 & 2 & 2 & 2 \\
\hline Prospective calculation of the sample size & 0 & 0 & 0 & 0 \\
\hline An adequate control group & 2 & 2 & 2 & 2 \\
\hline Contemporary groups & 1 & 0 & 1 & 1 \\
\hline Baseline equivalence of groups & 2 & 2 & 2 & 2 \\
\hline Adequate statistical analyses & 2 & 2 & 2 & 1 \\
\hline Total score & 19 & 17 & 18 & 17 \\
\hline
\end{tabular}




\begin{tabular}{|c|c|c|c|c|c|c|c|c|}
\hline & Study or Subgroup & $\begin{array}{r}\text { Drain } \\
\text { Events }\end{array}$ & Total & $\begin{array}{l}\text { No drai } \\
\text { Events }\end{array}$ & & Weight & $\begin{array}{l}\text { Risk Difference } \\
\text { M-H, Fixed, } 95 \% \mathrm{Cl}\end{array}$ & $\begin{array}{c}\text { Risk Difference } \\
\text { M-H, Fixed, } 95 \% \mathrm{Cl}\end{array}$ \\
\hline & Blank 2003 & 0 & 18 & 0 & 12 & $1.8 \%$ & $0.00[-0.13,0.13]$ & \\
\hline & Brown 2004 & 0 & 42 & 0 & 41 & $5.1 \%$ & $0.00[-0.05,0.05]$ & \\
\hline & Diab 2012 & 6 & 285 & 5 & 117 & $20.6 \%$ & $-0.02[-0.06,0.02]$ & \\
\hline & Kanayama 2010 & 0 & 298 & 0 & 262 & $34.6 \%$ & $0.00[-0.01,0.01]$ & 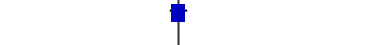 \\
\hline & Payne 1996 & 2 & 103 & 1 & 97 & $12.4 \%$ & $0.01[-0.02,0.04]$ & \\
\hline & Sen 2005 & 0 & 41 & 0 & 38 & $4.9 \%$ & $0.00[-0.05,0.05]$ & \\
\hline & Walid 2012 & 10 & 285 & 3 & 117 & $20.6 \%$ & $0.01[-0.03,0.05]$ & \\
\hline & Total $(95 \% \mathrm{Cl})$ & & 1072 & & 684 & $100.0 \%$ & $-0.00[-0.01,0.01]$ & \\
\hline & Total events & 18 & & 9 & & & & \\
\hline & $\begin{array}{l}\text { Heterogeneity: } \mathrm{Chi}^{2}= \\
\text { Test for overall effect: }\end{array}$ & $\begin{array}{l}1.87, d f=6 \\
Z=0.21(P\end{array}$ & $\begin{array}{l}6(P=0 \\
P=0.83\end{array}$ & $\begin{array}{l}0.93) ; 1^{2}=0 \\
\text { 3) }\end{array}$ & & & & 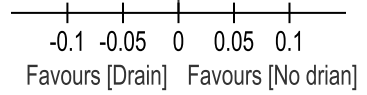 \\
\hline
\end{tabular}

\section{Results}

Literature search

A total of 396 potential studies were identified with the primary search strategy. Of these studies, 388 reports were excluded according to the eligibility criteria. No additional studies were obtained after the reference review. Ultimately, four non-RCTs and four RCTs [10-15, 18, 19] were eligible for data extraction and meta-analysis, as indicated by the flowchart in Fig. 1. These studies involved a total of 1133 patients in the drainage group and 771 patients in the no drainage group.

\section{Study characteristics}

The main characteristics of the included studies are reported in Table 1. Statistically, similar baseline characteristics were observed between the two groups. The sample sizes of included studies ranged from 30 to 560 patients. The surgical procedures of the four studies were single-level lumbar decompression surgeries [13-15, 18]. The surgical procedures of three studies were posterior spinal fusion and instrumentation $[10,12,19]$. In Brown's studies, the surgical procedure was extensive lumbar spine surgery [11].

\section{Risk of bias assessment}

The quality of the RCTs was assessed according to the Cochrane Handbook for Systematic Review of Interventions. Four RCTs met the inclusion criteria. Mirzai et al. reported that randomization was performed by flipping a coin; the three other RCTs provided randomization methods. Adequate concealment of allocation was unclear for two RCTs [10, 18]. None of the RCTs reported blinding methods. The MINORS scores were 17-19 for the non-RCTs [12, 13, 15, 19]. The methodological quality assessment is illustrated in Fig. 2 (RCTs) and Table 2 (non-RCTs).

\section{Outcomes for meta-analysis \\ Wound infection}

Details regarding wound infection were available in seven studies $[10-15,19]$. There was significant heterogeneity $\left(\chi^{2}=1.87, d f=6, I^{2}=0 \%, P=0.93\right)$; therefore, a fixed model was applied. Pooling of the results demonstrated

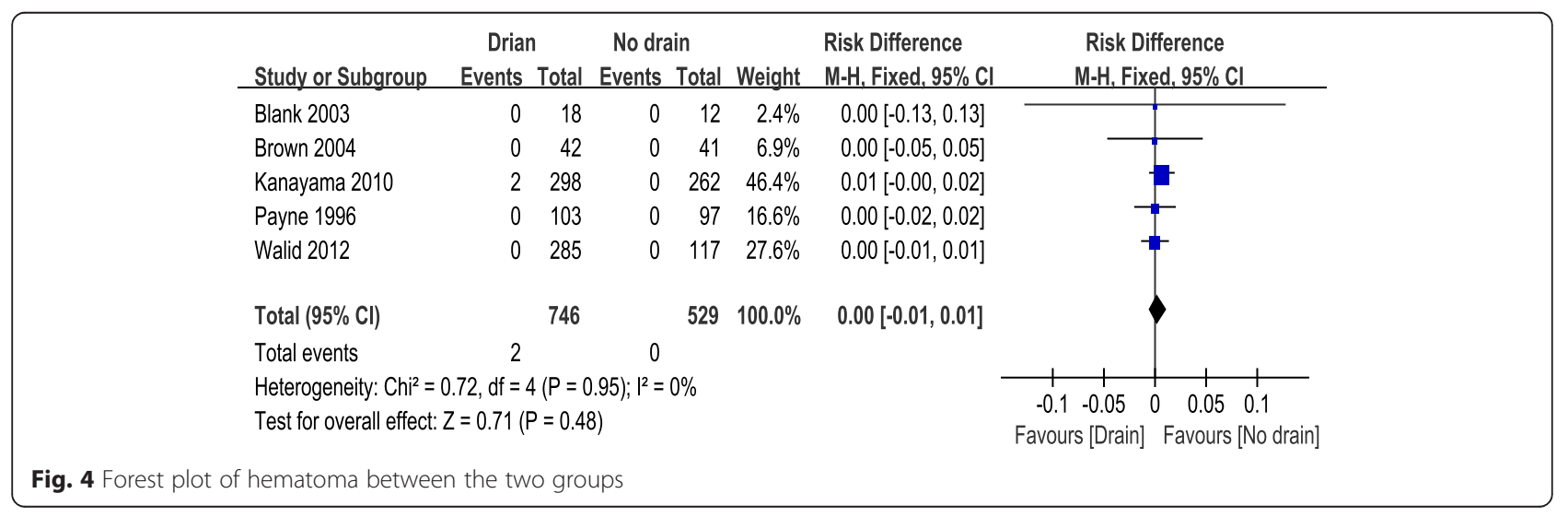




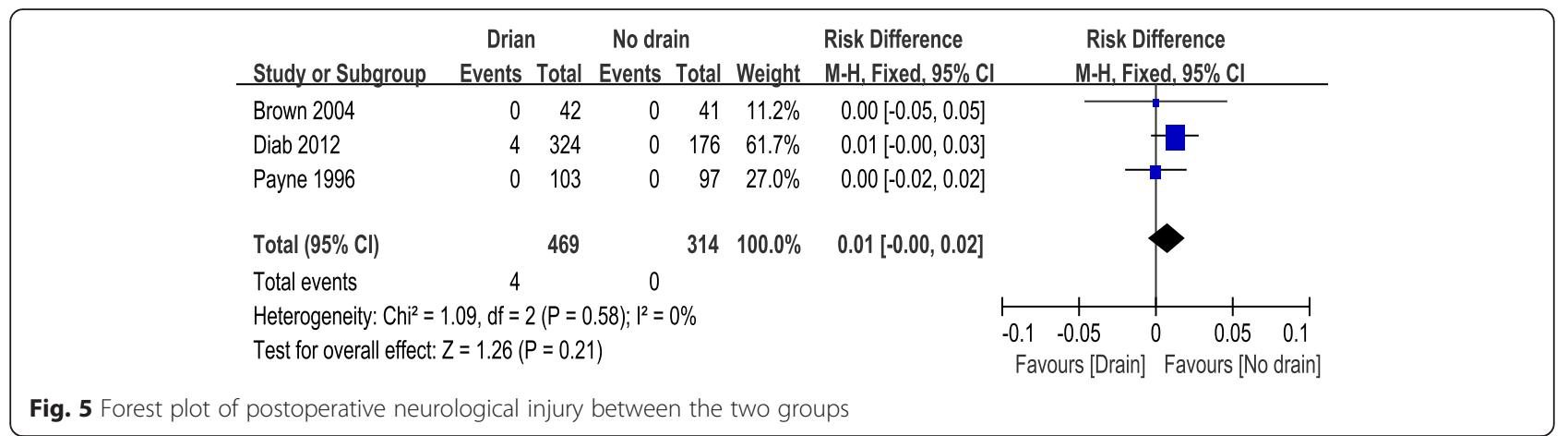

that wound infection showed no significant difference between the two groups $(\mathrm{RD}=-0.0 ; 95 \% \mathrm{CI},-0.01$ to 0.01; $P=0.83$; Fig. 3 ).

\section{Hematoma}

Five articles reported the incidence of hematoma $[10,11,13,14,19]$. Significant heterogeneity was found, so a fixed model was used $\left(\chi^{2}=0.72, d f=4\right.$, $\left.I^{2}=0 \%, P=0.72\right)$. There was no significant difference between the drain group and the no drain group regarding hematoma $(\mathrm{RD}=0.0 ; 95 \% \mathrm{CI},-0.01$ to $0.01 ; P=0.48$; Fig. 4 ).

\section{Postoperative neurological injury}

Relevant data regarding postoperative neurological injury were documented in three articles [11, 12, 14]. Significant heterogeneity was found, so a fixed model was used $\left(\chi^{2}=1.09, d f=2, I^{2}=0 \%, P=0.58\right)$. There was no significant difference between the drain group and the no drain group regarding postoperative neurological injury $(\mathrm{RD}=0.01 ; 95 \% \mathrm{CI},-0.00$ to $0.02, P=$ 0.21; Fig. 5).

\section{Estimated blood loss}

Three studies reported estimated blood loss [10-12]. Significant heterogeneity was found, so a random-effects model was used $\left(\chi^{2}=5.19, d f=2, I^{2}=61 \%, P=0.07\right)$. There was no significant difference between the drain group and the no drain group regarding postoperative neurological injury $(\mathrm{MD}=-37.12 ; 95 \% \mathrm{CI},-171.11$ to 96.88; $P=0.59$; Fig. 6).

\section{Postoperative dressing saturation}

Postoperative dressing saturation was reported in two trials [10, 11]. For dry dressing drainage, significant heterogeneity was shown between the pooled results; thus, a random-effects model was performed. There was no significant difference between the groups ( $R D=$ $0.19 ; 95 \% \mathrm{CI},-0.20$ to $0.58 ; P=0.33)$. For moderate dressing drainage, significant heterogeneity was shown between the pooled results; thus, a random-effects model was performed. There was no significant difference between the groups ( $\mathrm{RD}=0.00 ; 95 \% \mathrm{CI},-0.40$ to $0.40 ; P=0.99$ ). For saturated dressing drainage, no significant heterogeneity was shown between the pooled results; thus, a fixed model was performed. There were significant differences between the groups ( $\mathrm{RD}=-0.23 ; 95 \% \mathrm{CI},-0.38$ to $-0.09 ; P=0.002$ ).

\section{Discussion}

The most important finding of the present meta-analysis was that the use of drainage in posterior spinal surgery decreased saturated dressing drainage, but it did not reduce postoperative wound infection, hematoma, neurological injury, or estimated blood loss. Furthermore, no significant differences were found in dry or moderate dressing drainage.

Followed strict searching, four non-RCTs $[12,13,15,19]$ and four RCTs [10, 11, 14, 18] met the inclusion criteria for the meta-analysis. There were biases for randomization, concealment of allocation, and blinding methods in the

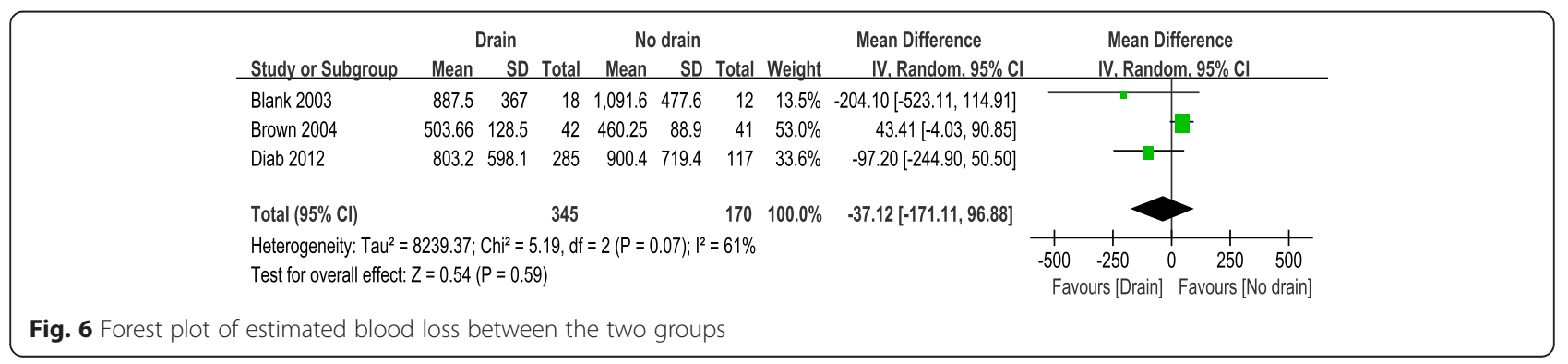


RCTs. The quality assessment scores of non-RCTs ranged from 17 to 19. No prospective calculation of the sample sizes was described in the non-RCTs. In addition, the contemporary groups were biased. All of these shortcomings weakened the level of evidence and should be considered when interpreting the findings of the present meta-analysis.

Wound infection is a common complication after posterior spinal surgery, increasing morbidity and medical costs. Spinal surgeons have advocated closed suction drainage due to a fear of infection [20,21]. The present meta-analysis found no significant difference in the incidence of wound infection. The incidence of infection was $1.68 \%$ in the closed suction drainage group and $1.32 \%$ in the no drainage group.

In theory, a hematoma in the wound is an excellent culture medium for bacterial growth. In spinal surgery, symptomatic epidural hematomas can cause spinal cord compression and even paralysis [22]. The present metaanalysis found no significant difference in the incidence of hematomas. In Mirzai et al.'s study, epidural hematomas were measured by magnetic resonance imaging (MRI) examinations [18]. They found that the group with drains had significantly fewer patients with hematomas and significantly more patients with no hematomas. However, none of the hematomas had significant effects on the recovery of any patients.

Two of the included studies reported postoperative dressing saturation from the wounds $[10,11]$. The pooled data demonstrated that the number of patient with saturated dressings was larger in the no drainage group. Saturated dressings reflected leakage of blood from wounds without drainage without the formation of hematoma.

Some studies showed that drainage was associated with significant blood loss and transfusion requirements [19]. In our meta-analysis, the pooled data demonstrated that drainage did not increase blood loss. Blank et al. reported that the transfusion requirements were similar for both groups [10]. In Walid et al.'s study, an increased rate of allogeneic blood transfusion was noted with posthemorrhagic anemia and drain use [19].

There were several potential limitations of our metaanalysis: (1) only four RCTs and four non-RCTs were identified, and the sample sizes of the included studies were relatively small; (2) there were some methodological weaknesses in the included studies; and (3) some data were incomplete, and we failed to conduct metaanalysis of factors such as transfusion requirements.

\section{Conclusions}

In summary, the use of drainage in posterior spinal surgery did not decrease infection, hematoma, or postoperative neurological injury. There was no obvious evidence to support the application of closed suction drains for posterior spinal surgery. Because of the limited quality of the evidence currently available, more high-quality RCTs with better experimental designs and larger patient samples should be performed.

\section{Competing interests}

The authors declare that they have no competing interests.

\section{Authors' contributions}

YCL and YML conceived of the design of the study. YCL and YML performed and collected the data and contributed to the design of the study. YCL and JM prepared and revised the manuscript. All authors read and approved the final content of the manuscript.

\section{Acknowledgements}

None.

\section{Author details}

${ }^{1}$ Department of Spine Surgery, Tianjin Hospital, Tianjin 300211, People's Republic of China. ${ }^{2}$ Department of Rehabilitation, Tianjin Hospital, Tianjin 300211, People's Republic of China.

Received: 13 December 2015 Accepted: 19 January 2016

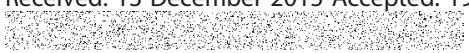

\section{References}

1. Holt BT, Parks NL, Engh GA, Lawrence JM. Comparison of closed-suction drainage and no drainage after primary total knee arthroplasty. Orthopedics. 1997;20(12):1121-4. discussion 24-5.

2. Kim YH, Cho SH, Kim RS. Drainage versus nondrainage in simultaneous bilateral total knee arthroplasties. Clin Orthop Relat Res. 1998;Feb(347):188-93.

3. Li ZJ, Fu X, Xing D, Zhang HF, Zang JC, Ma XL. Is tranexamic acid effective and safe in spinal surgery? A meta-analysis of randomized controlled trials. Eur Spine J. 2013;22(9):1950-7.

4. Awad JN, Kebaish KM, Donigan J, Cohen DB, Kostuik JP. Analysis of the risk factors for the development of post-operative spinal epidural haematoma. J Bone Joint Surg (Br). 2005;87(9):1248-52.

5. Kou J, Fischgrund J, Biddinger A, Herkowitz H. Risk factors for spinal epidural hematoma after spinal surgery. Spine (Phila Pa 1976). 2002;27(15):1670-3.

6. Parker MJ, Roberts CP, Hay D. Closed suction drainage for hip and knee arthroplasty. A meta-analysis. J Bone Joint Surg Am. 2004;86-A(6):1146-52.

7. Scuderi GJ, Brusovanik GV, Fitzhenry LN, Vaccaro AR. Is wound drainage necessary after lumbar spinal fusion surgery? Med Sci Monit. 2005;1 1(2): CR64-6.

8. Chen ZY, Gao Y, Chen W, Li X, Zhang YZ. Is wound drainage necessary in hip arthroplasty? A meta-analysis of randomized controlled trials. Eur J Orthop Surg Traumatol. 2014:24(6):939-46.

9. Zhang QD, Guo WS, Zhang Q, Liu ZH, Cheng LM, Li ZR. Comparison between closed suction drainage and nondrainage in total knee arthroplasty: a metaanalysis. J Arthroplasty. 2011;26(8):1265-72.

10. Blank J, Flynn JM, Bronson W, Ellman P, Pill SG, Lou JE, et al. The use of postoperative subcutaneous closed suction drainage after posterior spinal fusion in adolescents with idiopathic scoliosis. J Spinal Disord Tech. 2003; 16(6):508-12.

11. Brown MD, Brookfield KF. A randomized study of closed wound suction drainage for extensive lumbar spine surgery. Spine (Phila Pa 1976). 2004; 29(10):1066-8

12. Diab M, Smucny M, Dormans JP, Erickson MA, Ibrahim $K$, Lenke LG, et al. Use and outcomes of wound drain in spinal fusion for adolescent idiopathic scoliosis. Spine (Phila Pa 1976). 2012;37(11):966-73.

13. Kanayama M, Oha F, Togawa D, Shigenobu K, Hashimoto T. Is closed-suction drainage necessary for single-level lumbar decompression?: review of 560 cases. Clin Orthop Relat Res. 2010;468(10):2690-4.

14. Payne DH, Fischgrund JS, Herkowitz HN, Barry RL, Kurz LT, Montgomery DM. Efficacy of closed wound suction drainage after single-level lumbar laminectomy. J Spinal Disord. 1996;9(5):401-3.

15. Sen O, Kizilkilic O, Aydin MV, Yalcin O, Erdogan B, Cekinmez M, et al. The role of closed-suction drainage in preventing epidural fibrosis and its correlation with a new grading system of epidural fibrosis on the basis of MRI. Eur Spine J. 2005;14(4):409-14. 
16. Handoll HH, Gillespie WJ, Gillespie LD, Madhok R. The Cochrane Collaboration: a leading role in producing reliable evidence to inform healthcare decisions in musculoskeletal trauma and disorders. Indian. Orthop. 2008;42(3):247-51.

17. Slim K, Nini E, Forestier D, Kwiatkowski F, Panis Y, Chipponi J. Methodological index for non-randomized studies (minors): development and validation of a new instrument. ANZ J Surg. 2003;73(9):712-6.

18. Mirzai $H$, Eminoglu $M$, Orguc $S$. Are drains useful for lumbar disc surgery? A prospective, randomized clinical study. J Spinal Disord Tech. 2006;19(3):171-7.

19. Walid MS, Abbara M, Tolaymat A, Davis JR, Waits KD, Robinson 3rd JS, et al. The role of drains in lumbar spine fusion. World Neurosurg. 2012;77(3-4):564-8.

20. Chimenti P, Molinari R. Post-operative spinal epidural hematoma causing American Spinal Injury Association B spinal cord injury in patients with suction wound drains. J Spinal Cord Med. 2013;36(3):213-9.

21. Sokolowski MJ, Garvey TA, Perl 2nd J, Sokolowski MS, Cho W, Mehbod AA et al. Prospective study of postoperative lumbar epidural hematoma: incidence and risk factors. Spine (Phila Pa 1976). 2008;33(1):108-13.

22. Amiri AR, Fouyas IP, Cro S, Casey AT. Postoperative spinal epidural hematoma (SEH): incidence, risk factors, onset, and management. Spine J. 2013;13(2):134-40,

\section{Submit your next manuscript to BioMed Central} and we will help you at every step:

- We accept pre-submission inquiries

- Our selector tool helps you to find the most relevant journal

- We provide round the clock customer support

- Convenient online submission

- Thorough peer review

- Inclusion in PubMed and all major indexing services

- Maximum visibility for your research

Submit your manuscript at www.biomedcentral.com/submit

) Biomed Central 